\title{
Aus dem Vorwort zur 51.-56. Auflage
}

Die Richtsätze für die Nomenklatur der anorganischen Chemie sind inzwischen erschienen. Die deutsche Utbersetzung findet sich in den Chemischen Berichten Nr.7/1959 S. XLVII-LXXXV (Sonderdrucke können vom Verlag Chemie GmbH., Weinheim/Bergstr. bezogen werden). Diese Richtsätze sind bei dieser Neuauflage berücksichtigt worden. Es ist unbedingt erforderlich, daß der Anfänger sich von vornherein mit ihnen vertraut macht, damit er nicht später umlernen muß.

Frühjahr 1961

W. Rlemm

Münster i. W.

Universität
W. Fischer

Hannover

Technische Hochschule

\section{Vorwort zur 57.-62. Auflage}

Bei der Neubearbeitung sind zahlreiche sachliche Korrekturen entsprechend dem Fortschritt der Wissenschaft durchgeführt worden. Eine Reihe weiterer Änderungen des Textes sollen dazu dienen, durch klarere Formulierungen Mißverständnisse zu vermeiden und Erfahrungen beim praktischen Gebrauch des Werkes zu berücksichtigen.

Wir danken auch diesmal den Kollegen, die uns Verbesserungsvorschläge gemacht haben.

Oktober 1965

W. Klemm

Münster i. W.

Universität
W. Fischer

Hannover

Technische Hochschule 